\title{
Statistics of occurrence of pre-seismic anomalies in geoacous- tic emission and in atmospheric field
}

\author{
Mikhail Mishchenko ${ }^{1, \star}$ \\ ${ }^{1}$ Institute of Cosmophysical Researches and Radio Wave Propagation FEB RAS, \\ Paratunka, Kamchatsky Kray, Russia
}

\begin{abstract}
The paper presents the statistics of occurrence of anomalous disturbances in high-frequency geoacoustic emission of near surface sedimentary rocks and in atmosphric electric field by the ground surface before earthquakes. Long-term continuous series of geoacoustic emission measurements in 2003-2012 at "Mikizha" observation site and atmospheric electric field data obtained within summer-autumn period in 2006-2008 at "Mikizha" site and in 2009-2012 at "Karymshina" observation site were used for the analysis. Anomalous disturbances of the emission and of the field were compared with the earthquake catalogue of Kamchatka Branch of Geophysical Service RAS.
\end{abstract}

\section{Introduction}

Measurements of geoacoustic emission of the near surface sedimentary rocks (GAE) and of atmospheric electric field by the ground surface (AEF) are carried out in Kamchatka in the conditions of active seismic processes. Joint geoacoustic and atmospheric-electric measurements [1] indicate the fact that anomalous disturbances of these geophysical fields occur during seismically calm periods and at the final stage of earthquake preparation and are associated with the dynamics of the deformation process of the near surface sedimentary rocks. Thus, statistics of occurrence of such disturbances before earthquakes both in geoacoustic emission and in atmospheric electric field is of interest.

\section{Methods of investigation}

To analyze the preseismic disturbances, we used a long-term continuous series of geoactoustic measurements of the period from 2003 to 2013 from "Mikizha" site and AEF measurement data carried out during the summer-autumn period in 2005-2008 at "Mikizha" site and in 2009-2012 at "Karymshina" site. Anomalous disturbances of geoacoustic emission and those of atmospheric electric field were compared with the regional earthquake catalogue of Kamchatka Branch of Geophysical Service RAN (http://www.emsd.ru/ts/). Only GAE and AEF disturbances registered in fair weather conditions (slightly changing pressure, absence of rain and wind of more than $6 \mathrm{~m} / \mathrm{s}$ ) were under consideration.

\footnotetext{
^e-mail: micle@ikir.ru
} 


\section{Results of investigation and discussion}

Analysis of the data of geoacoustic observations in seismically active regions showed that anomalous disturbances of geoacoustic emission are sometimes registered before strong earthquakes. They appear as sudden increases of acoustic pressure in kilohertz frequency range $P s$ [2, 3]. An example of such a disturbance of geoacoustic emission is shown in Fig. 1a. 266 disturbances of GAE were detected for the period of 20032007. From their analysis, the following criteria for disturbance detection were selected: $P s$ amplitude averaged within 5-minute interval should exceed the GAE background value by more than 4 times with the duration of not less than $15 \mathrm{~min}$. Averages of $P s$ amplitude for the calmest day period within the closest ten days before a disturbance were taken as GAE background level [4].

Analysis of the data of atmospheric-electric observations in seismically active regions showed that anomalous disturbances of electric field are sometimes registered before strong earthquakes. As such, we usually consider bay decreases of field potential gradient $V^{\prime}$ up the change of a sign followed after a while by its recovery almost to the previous level [5-7]. An example of such a disturbance of AEF is shown in Fig. $1 b$.

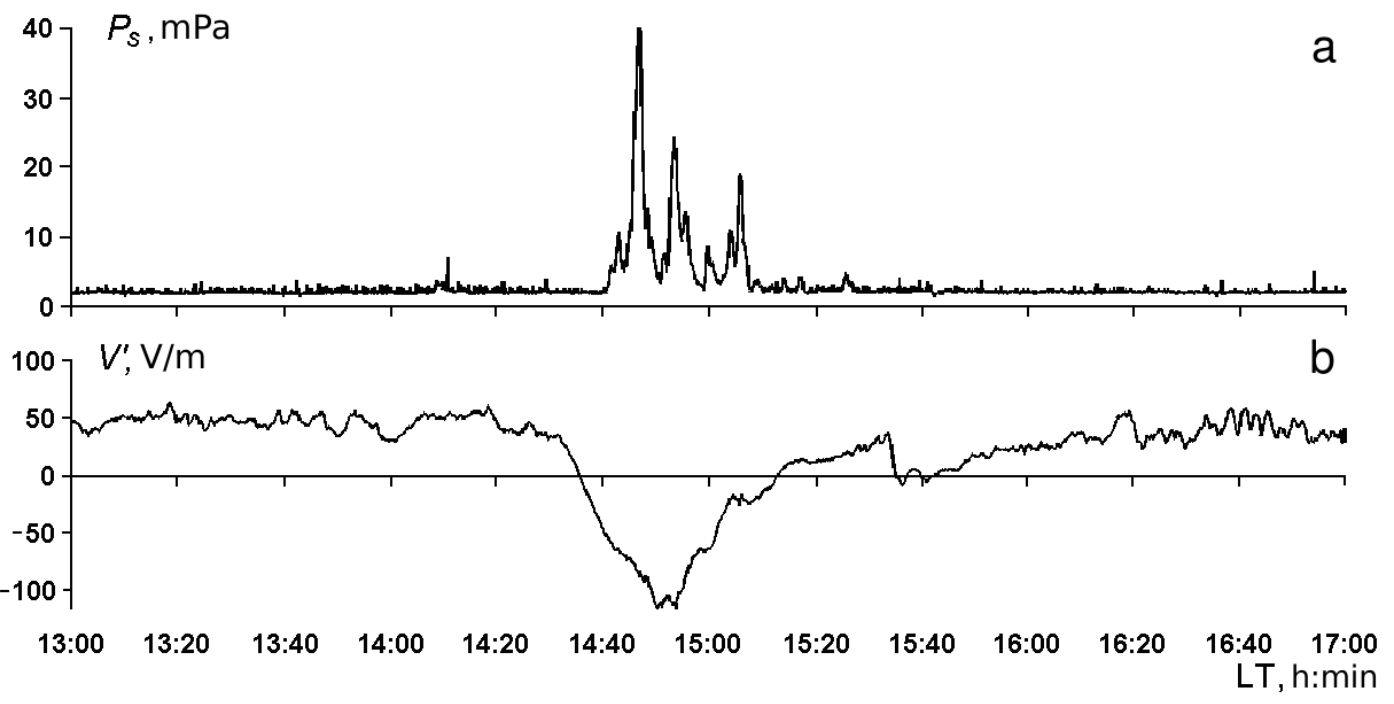

Figure 1. Example of simultaneous disturbances of acoustic pressure $P s$ in kilohertz frequency range (a) and that of potential gradient $V^{\prime}$ (b) in the experiment on August 22, 2006.

Taking into account that atmospheric-electric measurements were carried out during the summerautumn periods and lasted for only about three month a year, we did not receive enough data on preseismic disturbances of AEF to determine the criteria for their detection. Thus, the criteria were chosen based on the analysis of preseismic characteristics of AEF in Kamchatka. The analysis was carried out in the paper [7] for a continuous period of 1997-2002. The minimum duration of AEF disturbances is 15-20 min, and the minimum amplitude of bay decreases of the potential gradient $V^{\prime}$ is $-100 \mathrm{~V} / \mathrm{m}$.

Geoacoustic and atmospheric-electric disturbances occur almost simultaneously and are comparable in duration. Thus, in the further analysis, just like for GAE disturbances, we distinguished 
preseismic AEF disturbances with the duration of more than 15 min and the minimum decrease of the potential gradient $V^{\prime}$ equal to $-100 \mathrm{~V} / \mathrm{m}$ that agrees with the results obtained in the paper [7].

Taking into account the criteria for GAE disturbance detection, we analyzed geoacoustic data series from "Mikizha" site registered within 2003-2012. Anomalous disturbances of geoacoustic emission registered in fair weather conditions were detected. From the regional seismic catalogue, we chose two groups of earthquakes with the energy classes $11.0<K s \leq 12.0, K s>12.0$ and epicentral distances to the site $D \leq 240, D \leq 350$, respectively. Such distances were selected according to the analysis of GAE disturbance data [3] and corrected using the model studies [8] as the base. In the result of modeling [4], the time interval from two days and a half to 5 hours before an earthquake was chosen to search for GAE disturbances. The chosen earthquakes were compared with GAE anomalous disturbances. Presence of GAE disturbances before 107 earthquakes was considered. The results are shown in Table 1.

Table 1. Results of comparison of earthquakes with GAE anomalous disturbances

\begin{tabular}{|c|c|c|c|c|c|c|}
\hline \multicolumn{6}{|c|}{$11.0<K s \leq 12.0$} & \multicolumn{3}{c|}{$K s>12.0$} \\
\hline Energy class & \multicolumn{3}{|c|}{ Earthquakes } \\
\hline Year & Total & with GAE disturbances & $\%$ & All & with GAE disturbances & $\%$ \\
\hline 2003 & 7 & 5 & 71.4 & 3 & 3 & 100 \\
2004 & 4 & 2 & 50 & 6 & 6 & 100 \\
2005 & 1 & 0 & 0 & 2 & 2 & 100 \\
2006 & 7 & 5 & 71.4 & 4 & 3 & 75 \\
2007 & 6 & 5 & 83.3 & 3 & 3 & 100 \\
2008 & 5 & 4 & 80 & 6 & 3 & 50 \\
2009 & 8 & 6 & 75 & 1 & 0 & 0 \\
2010 & 5 & 1 & 20 & 7 & 3 & 42.9 \\
2011 & 17 & 9 & 52.9 & 3 & 3 & 100 \\
2012 & 9 & 5 & 55.6 & 3 & 2 & 66.7 \\
\hline Total & 69 & 42 & 60.9 & 38 & 28 & 73.7 \\
\hline
\end{tabular}

According to Table 1, GAE disturbances were observed before 42 out of 69 earthquakes with the characteristics $11.0<K s \leq 12.0$ and $D \leq 240 \mathrm{~km}$ and before 28 out of 38 earthquakes with $K s>12.0$ and $D \leq 350 \mathrm{~km}$.

The results of comparison of geoacoustic emission with the earthquakes with energy class $K s>$ 9.0 showed that $36.8 \%$ of GAE disturbances occured before earthquakes. Thus, the percentage of false alarms is $63.2 \%$.

In terms of the criteria formulated for detection of AEF disturbances, we analyzed the series of atmospheric-electric data for the periods of summer-autumn measurements at "Mikizha" site (2006, 2007 and 2008) and at "Karymshina" site (2009, 2011 and 2012). Anomalous disturbances of atmospheric electric field by the ground surface were detected during fair weather conditions described above.

Just like for GAE, two groups of earthquakes with energy classes $11.0<K s \leq 12.0$ and $K s>$ 12.0 and epicentral distances $D \leq 240$ and $D \leq 350 \mathrm{~km}$ were chosen. As long as geoacoustic emission is the indicator of change of the near surface rock deformation state, time intervals of two days and a half before earthquakes were chosen according to [4] to search for AEF disturbances. The selected earthquakes were compared with AEF anomalous disturbances. For "Mikizha" site, presence 
of AEF disturbances was considered before 19 earthquakes and for "Karymchina" site we analyzed 11 earthquakes. The results of comparison are shown in Table 2.

Table 2. Results of comparison of earthquakes with AEF anomalous disturbances

\begin{tabular}{|c|c|c|c|c|c|}
\hline \multicolumn{6}{|c|}{ Earthquakes } \\
\hline \multicolumn{2}{|c|}{ Energy class } & \multicolumn{2}{|c|}{$11.0<K s \leq 12.0$} & \multicolumn{2}{c|}{$K s>12.0$} \\
\hline Observation site & Year & Total & with AEF disturbances & All & with AEF disturbances \\
\hline \multirow{3}{*}{ "Mikizha" } & 2006 & 4 & 1 & 4 & 1 \\
& 2007 & 3 & 1 & 0 & 0 \\
& 2008 & 3 & 0 & 2 & 1 \\
\hline \multirow{3}{*}{ "Karymchina" } & 2009 & 2 & 2 & 0 & 0 \\
& 2011 & 3 & 1 & 1 & 1 \\
& 2012 & 4 & 1 & 1 & 0 \\
\hline & Total & 19 & 6 & 8 & 3 \\
\hline
\end{tabular}

According to Table 2, AEF disturbances were observed before 2 earthquakes out of 10 with characteristics $11.0<K s \leq 12.0$ and $D \leq 240 \mathrm{~km}$ and before 2 earthquakes out of 6 with $K s>12.0$ and $D \leq 350 \mathrm{~km}$ at "Mikizha" site. At "Karymshina" site, AEF disturbances were observed before 4 out of 9 earthquakes with the characteristics $11.0<K s \leq 12.0$ and $D \leq 240 \mathrm{~km}$ and before 1 out of 2 earthquakes with $K s>12.0$ and $D \leq 350 \mathrm{~km}$.

\section{Conclusions}

Based on the analysis of the observations of geoacoustic emission and of atmospehric electric field, criteria for detection of their anomalous disturbances were suggested. They allowed us to distinguish disturbances preceding the earthquakes in high-frequency geoacoustic emission and in atmospheric electric field by the ground surface in Kamchatka. The number of such preseismic disturbances in the electric field is much less than that in GAE since atmospheric-electric measurements were carried out only during summer-autumn periods and lasted for about three month a year.

\section{References}

[1] O. P. Rulenko, Yu. V. Marapulets, M. A. Mishchenko, Journal of Volcanology and Seismology, 8:3, 183-193 (2014)

[2] V. A. Morgunov et al., Volcanology and Seismology, 13:4, 516-518 (1992)

[3] A. V. Kuptsov, Izvestiya. Physics of the Solid Earth, 41:10, 825-831 (2005)

[4] M. A. Mishchenko, Bulletin KRASEC. Phys.\&Math. Sci., 2:1, 56-64 (2011)

[5] O. P. Rulenko, A.V. Ivanov, A. V. Shumeyko, Doklady Earth Sciences, 326:6, 980-982 (1992)

[6] O. P. Rulenko, Volcanology and Seismology, 22:4, 435-451 (2001)

[7] S. E. Smirnov, Geomagnetism and Aeronomy, 45, 265-269 (2005)

[8] I. P. Dobrovol'skiy Mekhanika podgotovki tektonicheskogo zemletryaseniya (IFZ AN SSSR, Moscow, 1984), 189 (in Russian) 